\title{
Características agronômicas e o estado nutricional de cultivares de girassol irrigado
}

\author{
Leonardo A. de Aquino', Fred D. B. da Silva² \& Paulo G. Berger ${ }^{3}$
}

\begin{abstract}
RESUMO
Objetivou-se, neste trabalho, avaliar o estado nutricional, caracteres agronômicos e a produtividade de cultivares de girassol sob irrigação. Os cultivares Embrapa 122 V-2000, Hélio 250, Hélio 251, Hélio 253, Hélio 358, Hélio 360, IAC larama, Dow Agroscience M 734 e MG 02, foram semeados em blocos ao acaso, com quatro repetições. O número de folhas por planta no florescimento foi maior nos híbridos Hélio 250, Hélio 251, Hélio 253, Hélio 358, Hélio 360, Dow Agroscience M 734 e MG 02, em relação aos cultivares de polinização aberta Embrapa 122 V-2000 e IAC larama. Os teores foliares de N, P, K, Ca, Mg e S foram 40,91; 3,51; 35,91; 33,91; 6,23 e 7,88 $\mathrm{g} \mathrm{kg}^{-1}$, respectivamente. Os cultivares Embrapa 122 $\mathrm{V}$-2000 e IAC-larama apresentaram teor de $\mathrm{P}$ na folha índice menor que os demais cultivares. Os teores foliares de Zn, Cu, Fe e o Mn foram 75,15; 24,11; 98,39 e 348,10 $\mathrm{mg} \mathrm{kg}^{-1}$, respectivamente. O teor médio de $B$ na folha índice nos híbridos e nas variedades de polinização aberta foi de 119,25 e 140,35 mg kg-1, respectivamente. Os cultivares Hélio 250, Hélio 251, Hélio 253, Hélio 358, Hélio 360, Dow Agroscience M 734 e MG 02 apresentaram maior produtividade que o Embrapa 122 V-2000 e o IAC Iarama.
\end{abstract}

Palavras-chave: Helianthus annuus, nutrientes, híbrido, variedade

\section{Agronomic characteristics and nutritional status of irrigated sunflower cultivars}

\begin{abstract}
This work aimed to assess nutritional status, agronomic characteristics, and productivity of sunflower cultivars under irrigation. Embrapa 122 V-2000, Hélio 250, Hélio 251, Hélio 253, Hélio 358, Hélio 360, IAC larama, and Dow Agroscience M 734 and MG 02 cultivars were sown in randomized block design with four replications. The number of leaves per plant in full bloom was higher in hybrid Hélio 250, Hélio 251, Hélio 253, Hélio 358, Hélio 360 and Dow Agroscience MG 734 and M 02 related to open-pollinated cultivars Embrapa 122 V-2000 and IAC larama. Foliar contents of N, P, K, Ca, Mg, and S were 40.91, 3.51, $35.91,33.91,6.23$, and $7.88 \mathrm{~g} \mathrm{~kg}^{-1}$, respectively. Embrapa $122 \mathrm{~V}-2000$ and IAC-larama cultivars showed an average content of $\mathrm{P}$ in the index leaf lower than the other cultivars. Foliar contents of $\mathrm{Zn}, \mathrm{Cu}, \mathrm{Fe}$, and Mn were $75.15,24.11,98.39$, and $348.10 \mathrm{mg} \mathrm{kg}^{-1}$, respectively. Mean content of $B$ in index leaf of hybrid and open-pollinated varieties was 119.25 and $140.35 \mathrm{mg} \mathrm{kg}^{-1}$, respectively. Hélio 250, Hélio 251, Hélio 253, Hélio 358, Hélio 360, and Dow Agroscience M 734 and MG 02 cultivars had higher productivity than Embrapa $122 \mathrm{~V}-2000$ and IAC larama.
\end{abstract}

Key words: Helianthus annuus, nutrients, hybrid, variety 


\section{INTRODUÇÃO}

O cultivo do girassol vem-se consolidando como cultura alternativa em sucessão ao milho e à soja, pela tolerância ao déficit hídrico. Sua elevada capacidade de ciclagem de nutrientes proporcionada pela absorção em maiores profundidades e sua reduzida taxa de exportação de nutrientes, têm favorecido o interesse dos produtores pela cultura (Castro \& Oliveira, 2005). Ainda assim, sua produtividade está aquém do seu potencial. A produtividade média dos cultivares no Brasil na safra 2010/2012 foi de $1312 \mathrm{~kg} \mathrm{ha}^{-1}$ (CONAB, 2011).

A capacidade para expressar a máxima produtividade de aquênios está relacionada, em parte, com uma nutrição mineral adequada da planta. Para isto, o conhecimento dos teores dos nutrientes no solo e nas folhas é imprescindível para uma correção adequada da fertilidade do solo (Castro \& Oliveira, 2005). Neste caso, relacionar os teores de nutrientes nas folhas com a produtividade de aquênios esperada é relevante para o manejo eficiente da adubação na cultura. De forma adicional a este recurso a exigência particular de cada cultivar deve ser considerada no intuito de melhorar a precisão no manejo da adubação. Para isto, avaliações nutricionais podem contribuir para indicar os teores foliares adequados conforme a produtividade de aquênios (Prado \& Leal, 2006; Santos et al., 2010; Zobiole et al., 2010a; 2010b).

O rendimento de aquênios de girassol pode ser limitado quando o déficit hídrico prejudica o crescimento da planta (Castro et al., 2006), especialmente das folhas baixeiras (Toureiro et al., 2007). O maior número de folhas durante o enchimento de aquênios tem relação direta com o estado nutricional da planta e este, por sua vez, com a produtividade do girassol (Palmer et al., 1996; Biscaro et al., 2008; Ivanoff et al., 2010; Aguiar Neto et al., 2010; Zobiole et al., 2010b). Conforme Zobiole et al. (2010b), quando o híbrido BRS 191 foi cultivado em densidade de 42.858 plantas ha $^{-1}$, com espaçamento de 70 $\mathrm{cm}$ e sem déficit hídrico e nutricional, uma quantidade de 35 folhas, $0,8 \mathrm{~m}^{2}$ de área foliar e $2 \mathrm{~m}$ de altura, foi imprescindível para obter altas produtividades de aquênios.

Quando ocorre déficit nutricional, especialmente do nitrogênio e do fósforo, o número e a área de folhas são reduzidos (Palmer et al., 19 96; Prado \& Leal, 2006). A sensibilidade à baixa concentração do nitrogênio e do fósforo também promove o decréscimo da altura e do diâmetro do caule (Prado \& Leal, 2006; Ivanoff et al., 2010). Desta forma, avaliações dos caracteres agronômicos durante a fase vegetativa e reprodutiva associadas ao estado nutricional podem explicar melhor o desempenho da produtividade das cultivares em competição. Castro \& Oliveira (2005) comentaram que a maior absorção de nutrientes ocorre durante a fase reprodutiva, pois coincide com o período de maior acúmulo de nutrientes nas folhas.

No caso da cultivar BRS 191 no estádio reprodutivo a folha foi o principal órgão responsável pela redistribuição dos nutrientes móveis na planta durante o enchimento dos aquênios, exceto para o potássio. Para este nutriente a maior concentração estava localizada no pecíolo e no caule. Referidas observações evidenciaram a importância do crescimento foliar e do caule como fator determinante para o acúmulo de nutrientes e, por conseguinte, para a produtividade de aquênios (Zobiole et al., 2010a).

Desta forma, avaliar caracteres agronômicos, assim como o estado nutricional, pode fornecer informações úteis no que diz respeito à capacidade produtiva do cultivar. Assim, objetivouse avaliar o estado nutricional, caracteres agronômicos e a produtividade de cultivares de girassol, cultivados sob irrigação.

\section{Material e Métodos}

O experimento foi desenvolvido durante o período de junho a setembro de 2009 na Unidade Experimental do Instituto Federal de Educação, Ciência e Tecnologia no Norte de Minas Gerais - Campus Januária. O clima da região foi classificado como tropical úmido, com inverno seco e verão chuvoso (Aw), de acordo com a classificação de Köppen, precipitação média anual de $850 \mathrm{~mm}$, umidade relativa média $60 \%$ e temperatura média anual de $27^{\circ} \mathrm{C}$. A área experimental está situada na latitude $15^{\circ} 28^{\prime} 55^{\prime}$ ' S, longitude $44^{\circ} 22^{\prime} 41^{\prime \prime} \mathrm{W}$ com altitude média de $474 \mathrm{~m}$.

Os dados meteorológicos durante o experimento foram registrados na estação meteorológica automática, a $300 \mathrm{~m}$ do experimento (Figura 1). O solo foi classificado como Neossolo Quartzarênico com 30\% de areia grossa, 57\% de areia fina, $3 \%$ de silte e $10 \%$ de argila. Para caracterizar quimicamente o solo, foram coletadas amostras com antecedência de 30 dias da semeadura (Tabela 1).

O preparo do solo foi realizado com uma aração na camada de $20 \mathrm{~cm}$ seguida de uma gradagem para destorroar e nivelar o solo. Na semeadura foram aplicados $250 \mathrm{~kg} \mathrm{ha}^{-1}$ do formulado 8-28-16. No estádio $V_{2}$ (2 folhas com pelo menos $4 \mathrm{~cm}$ de comprimento), foi feita capina manual e, no $\mathrm{V}_{4}$ (4 folhas com pelo menos $4 \mathrm{~cm}$ de comprimento) foram aplicados $40 \mathrm{~kg} \mathrm{ha}^{-1}$ de $\mathrm{N}$ via sulfato de amônio e $40 \mathrm{~kg} \mathrm{ha}^{-1}$ de $\mathrm{K}_{2} \mathrm{O}$ via cloreto de potássio. No estádio $\mathrm{V}_{8}$ ( 8 folhas com pelo menos $4 \mathrm{~cm}$ de comprimento) foram aplicados $40 \mathrm{~kg} \mathrm{ha}^{-1} \mathrm{de} \mathrm{N}$ via ureia e 20 $\mathrm{kg} \mathrm{ha}^{-1}$ de $\mathrm{K}_{2} \mathrm{O}$ via cloreto de potássio; nesta ocasião foi feita outra capina manual.

Os tratamentos consistiram das cultivares Embrapa 122 V-2000, Hélio 250, Hélio 251, Hélio 253, Hélio 358, Hélio 360, IAC Iarama, Dow Agroscience M 734 e MG 02. Adotou-se o delineamento em blocos ao acaso com quatro repetições. Foi realizado o semeio de 120.000 aquênios ha ${ }^{-1}$. Após sete dias da emergência realizou-se o desbaste para ajuste da população para 40.000 plantas ha $^{-1}\left(2,8\right.$ plantas $\left.\mathrm{m}^{-1}\right)$. Cada parcela experimental foi constituída de 4 linhas de $6 \mathrm{~m}$ espaçadas, 0,7 m. Foram consideradas úteis as duas linhas centrais, menos $0,5 \mathrm{~m}$ de cada extremidade.

Tabela 1. Características químicas do solo na camada de 0-20 cm

\begin{tabular}{|c|c|c|c|c|c|c|c|c|c|c|c|c|c|}
\hline $\mathrm{pH}$ & $P$ & K & $\mathrm{Ca}^{2+}$ & $\mathrm{Mg}^{2+}$ & $\mathrm{Al}^{3+}$ & $\mathrm{H}+\mathrm{Al}$ & $T$ & P-rem & $\mathrm{Fe}$ & $\mathrm{Cu}$ & $\mathrm{Zn}$ & Mn & B \\
\hline $\mathrm{H}_{2} \mathrm{O}$ & \multicolumn{2}{|c|}{$\mathrm{mg} \mathrm{dm}^{-3}$} & \multicolumn{5}{|c|}{$\mathrm{cmol}_{\mathrm{c}} \mathrm{dm}^{-3}$} & \multicolumn{6}{|c|}{$\mathrm{mq} \mathrm{dm}^{-3}$} \\
\hline 5,4 & 37,3 & 56 & 1,9 & 0,4 & 0,0 & 1,3 & 3,7 & 53,9 & 1,7 & 1,2 & 4,8 & 20,5 & 0,74 \\
\hline
\end{tabular}

Extratores: $\mathrm{P}, \mathrm{K}, \mathrm{Fe}, \mathrm{Cu}, \mathrm{Zn}, \mathrm{Mn}-$ Mehlich -1; $\mathrm{Ca}^{2+}, \mathrm{Mg}^{2+}, \mathrm{Al}^{3+}-\mathrm{KCl} 1 \mathrm{molL}^{-1} ; \mathrm{H}+\mathrm{Al}-\mathrm{Ca}(\mathrm{OAc})_{2} ;$ P-rem - Fósforo remanescente; $\mathrm{B}$ - Água quente 
A cultura foi irrigada por aspersão convencional. Utilizou-se espaçamento de $12 \times 12 \mathrm{~m}$ entre os aspersores, com vazão de $1,49 \mathrm{~m}^{3} \mathrm{~h}^{-1}$ e pressão de operação de 2,5 bar. Determinou-se o coeficiente de uniformidade de Christiansen (CUC), o qual foi de 85,6\%. Calculou-se a evapotranspiração de referência (ET $\left.\mathrm{ET}_{0}\right)$ com os dados meteorológicos diários, utilizando-se o método Penman Monteith (Allen et al., 2006). A evapotranspiração diária da cultura foi obtida pelo produto entre a $\mathrm{ET}_{0} \mathrm{e}$ os coeficientes de cultura para o girassol (Bernardo et al., 2006). Diariamente foi reposta uma lâmina evapotranspirada menos a precipitação efetiva.

Vinte dias após a emergência determinou-se a altura de 10 plantas ao acaso, na área útil, quantificando-se a distância do solo até o ápice foliar, com auxílio de uma fita métrica ocasião em que as folhas expandidas das referidas plantas foram contabilizadas. Quando 50\% das plantas da área útil emitiram o botão floral, foi quantificado o período entre a emergência das plântulas e a emissão da inflorescência; nesta ocasião mediuse a altura de plantas e se contabilizou o número de folhas emitidas. O período entre a semeadura e a floração plena foi quantificado quando $50 \%$ das plantas da área útil apresentaram todas as flores do capítulo abertas. Nesse estádio as folhas emitidas foram contabilizadas e a altura foi medida do solo até a inserção do capítulo.

No florescimento pleno de cada cultivar coletou-se a folha índice completamente expandida a partir do ápice. As folhas foram limpas com auxílio de algodão umedecido com uma solução aquosa com $0,1 \%$ de detergente neutro; em seguida, as folhas foram colocadas em estufa com ventilação forçada de ar a $70{ }^{\circ} \mathrm{C}$, até massa constante; após a secagem procedeuse à trituração em moinho tipo Wiley equipado com peneira de malha 1,27 mm; procedeu-se, posteriormente, à pesagem, digestão e quantificação dos teores de $\mathrm{N}, \mathrm{P}, \mathrm{K}, \mathrm{Mg}, \mathrm{Ca}, \mathrm{S}, \mathrm{Zn}$, $\mathrm{Mn}, \mathrm{Cu}, \mathrm{Fe}$ e B, de acordo com Malavolta et al. (1997).

Quando os aquênios apresentaram 13\% de umidade, foram feitas a colheita manual dos capítulos e a trilha mecânica para, em seguida, quantificar a massa de aquênios da área útil de cada parcela em kg ha-1 e determinar a massa de 1000 aquênios.

Os dados foram submetidos à análise de variância. As médias dos tratamentos foram comparadas pelo critério de Scott-Knott a 0,05 de probabilidade. Utilizou-se o software estatístico SAEG para o processamento de análise de variância e teste de média (SAEG, 2007).

\section{Resultados e Discussão}

Verificou-se que, aos 20 dias após emergência, a cultivar Embrapa 122 V-2000 foi a que apresentou maior crescimento em altura (Tabela 2). Entretanto, o número de folhas nos cultivares Hélio 358, Hélio 360 e Dow Agroscience MG 02 foi semelhante ao cultivar Embrapa 122 V-2000 embora com altura inferior a esta variedade. Entre os cultivares Hélio 250, Hélio 251, Hélio 253 e Dow Agroscience M 734, também houve divergência na altura, porém tiveram comportamento semelhante para o número de folhas. A cultivar IAC Iarama apresentou a menor altura e o número de folhas aos $20 \mathrm{DAE}$, entre as cultivares. Esses resultados estão de acordo com os obtidos por Zobiole et al. (2010b) quando avaliaram o crescimento do híbrido BRS 191 cultivado no espaçamento 0,7 com densidade de plantas de 42.858 plantas ha $^{-1}$. Referidos autores mencionaram que o girassol apresentou crescimento lento aos 30 dias após semeadura mesmo quando foi cultivado em condições hídricas e de disponibilidade térmica favoráveis de Londrina, PR.

De forma geral e a partir da emissão do botão floral, as cultivares duplicaram seu crescimento em altura quando comparados com a avaliação inicial (Tabela 2). Este ganho foi menos expressivo para o número de folhas. Este número torna-se decisivo para obter uma produção maior de aquênios, pois mantém uma relação direta com o estado nutricional da planta (Palmer et al., 1996; Biscaro et al., 2008; Ivanoff et al., 2010; Aguiar Neto et al., 2010; Zobiole et al., 2010b). Isto, pelo fato de as folhas serem órgãos fonte de nutrientes e compostos orgânicos para a formação dos aquênios. Relata-se que para cada 1000 aquênios por capítulo é necessária uma área foliar de 0,2 $\mathrm{m}^{2}$ (Castro \& Farias, 2005). Conforme Zobiole et al. (2010b), quando o cultivo do cultivar BRS 191 é produzido sem déficit hídrico e nutricional, uma quantidade de 35 folhas, $0,8 \mathrm{~m}^{2}$ de área foliar e $2 \mathrm{~m}$ de altura, é imprescindível para se obter altas produtividades de aquênio.

Para emitir o botão floral foram necessários 31 dias nas cultivares Embrapa 122 V-2000, Hélio 250 e Hélio 358; 34 dias para as cultivares IAC Iarama e Dow Agroscience M 734 e 37 dias para a Hélio 251, Hélio 253, Hélio 360 e Dow Agroscience MG 02 (Tabela 2). O maior crescimento em altura e número de folhas foi observado para Embrapa 122 V-2000 na emissão do botão floral, comportamento passível de ser função da sua

Tabela 2. Caracteres fenotípicos das cultivares de girassol aos 20 dias após emergência e na fase $R_{1}$

\begin{tabular}{|c|c|c|c|c|c|}
\hline \multirow{2}{*}{ Cultivar } & \multicolumn{2}{|c|}{ Caracteres aos 20 dias } & \multicolumn{3}{|c|}{ Caracteres na fase $\mathbf{R}_{1}{ }^{1}$} \\
\hline & Altura $(\mathrm{cm})$ & $N^{0}$ de folhas & Emissão do $\mathrm{BF}^{2}$ (dias) & Altura (cm) & $\mathrm{N}^{0}$ de folhas \\
\hline IAC larama & $17 \mathrm{e}$ & $7 c$ & $34 \mathrm{~b}$ & $51 \mathrm{C}$ & $11 \mathrm{c}$ \\
\hline Hélio 251 & $27 \mathrm{c}$ & $9 b$ & $37 \mathrm{a}$ & $69 \mathrm{~b}$ & $14 \mathrm{~b}$ \\
\hline Hélio 253 & $28 \mathrm{c}$ & $9 b$ & $37 \mathrm{a}$ & $68 b$ & $15 b$ \\
\hline Hélio 358 & $28 \mathrm{c}$ & $11 \mathrm{a}$ & $31 \mathrm{c}$ & $72 b$ & $16 b$ \\
\hline Dow Agroscience MG 02 & $30 \mathrm{~b}$ & $10 \mathrm{a}$ & $37 \mathrm{a}$ & $69 \mathrm{~b}$ & $14 \mathrm{~b}$ \\
\hline Média & 28 & 9 & 34 & 70 & 14 \\
\hline $\mathrm{F}$ & $63,3^{* *}$ & $5,2^{\star *}$ & $25,5^{* *}$ & $15,8^{* *}$ & $12,1^{* *}$ \\
\hline C.V. (\%) & 6,7 & 13,4 & 3,3 & 10,2 & 7,4 \\
\hline
\end{tabular}

${ }^{1} \mathrm{~A}$ inflorescência torna-se visível e é circundada pelas brácteas; ${ }^{2}$ Botão floral. Médias seguidas pela mesma letra na coluna não diferem entre si pelo teste Scott Knott a 0,05 de probabilidade 
precocidade. Esta característica referente ao cultivar Embrapa 122 V-2000 foi observada por Farias et al. (2000), Amabile et al. (2003) e Uchoa et al. (2011).

De forma adicional verifica-se que a cultivar Embrapa 122 V-2000 e a IAC Iarama apresentaram menor número de folhas em relação aos outras cultivares durante o florescimento pleno (Tabela 3). Isto sugere o uso de menores espaçamentos com o objetivo de melhorar a interceptação da radiação solar e garantir o controle de plantas daninhas desde que não haja déficit hídrico nem nutricional (Andrade et al., 2002). Braz \& Rossetto (2010) não constataram diferença significativa entre as densidades de 45.000 e 75.000 plantas ha ${ }^{-1}$ no espaçamento de $70 \mathrm{~cm}$ para o acúmulo de massa seca no caule, na folha, e nos aquênios da cultivar Embrapa 122 V-2000. Esses autores explicaram que a ausência de precipitação e temperaturas máximas de $36^{\circ} \mathrm{C}$ podem ter prejudicado o incremento de biomassa seca da planta.

Diferentemente, Silva et al. (2009) verificaram que o espaçamento entre linhas de $40 \mathrm{~cm}$ proporciona maiores produtividades de aquênios em relação aos 50, 70, 80 e $90 \mathrm{~cm}$ para uma população final de 45.000 plantas ha ${ }^{-1}$, para os híbridos Agrobel 960, BRHS 5 e Hélio 251.

A maior precocidade do cultivar Embrapa 122 V-2000 foi confirmada durante o florescimento pleno (Tabela 3). A maior precocidade desta cultivar e da IAC Iarama esteve associada ao menor número de folhas em relação as demais cultivares. De forma geral verifica-se, entre as cultivares, uma variação de 11 dias para completar o ciclo cultural. Em outras regiões brasileiras a cultivar Embrapa 122 V 2000 também apresentou menor ciclo em comparação a outras em teste (Farias Neto et al., 2000; Smiderle et al., 2005; Uchoa et al., 2011). Esta característica é interessante quando o cultivo do girassol é realizado em safrinha para evitar o estresse hídrico.

Verifica-se que as cultivares Embrapa 122 V-2000, IAC Iarama, Hélio 250, Hélio 360, e Dow Agroscience M 734 e MG 02 apresentaram maior massa de mil aquênios em relação às demais (Tabela 3). A massa de mil aquênios está de acordo com Silva et al. (2011) quando aplicaram diariamente uma lâmina de irrigação correspondente a $150 \%$ da evapotranspiração do tanque classe A; em outra ocasião Silva et al. (2009) constataram valores menores em relação ao presente estudo e explicaram que a massa de mil aquênios foi influenciada por uma quantidade maior de fibras em relação ao teor de óleo.
As cultivares apresentaram maior produtividade média (Tabela 3) em relação às obtidas por Farias Neto et al. (2000) e Porto et al. (2009). Esta elevada produtividade das cultivares comparada à obtida em outros estudos, pode estar relacionada às condições climáticas favoráveis ao cultivo do girassol (Figura 1) e à disponibilidade hídrica por meio da irrigação. Temperaturas entre 20 e $28^{\circ} \mathrm{C}$ são consideradas ideais para o desenvolvimento do cultivo da espécie (Castro \& Farias, 2005). Braz \& Rossetto (2010) mencionaram que o déficit hídrico e temperaturas elevadas, especialmente na fase de florescimento, prejudicam o acúmulo de matéria seca pelas plantas e a produtividade da cultura.

$\mathrm{O}$ teor de $\mathrm{N}$ na folha índice não diferiu entre as cultivares (Tabela 4). A faixa adequada de $\mathrm{N}$ na folha índice se situa de $35-$ $50 \mathrm{~g} \mathrm{~kg}^{-1}$ (Castro \& Oliveira, 2005). Neste experimento foram verificadas uma variação de 37,40 a $44,71 \mathrm{~g} \mathrm{~kg}^{-1}$ de $\mathrm{N}$ e uma produtividade de 2.888 a $4.631 \mathrm{~kg} \mathrm{ha}^{-1}$ entre as cultivares. Em estudo com o híbrido BRS-191 obteve-se o teor de $46 \mathrm{~g} \mathrm{~kg}^{-1} \mathrm{de}$ $\mathrm{N}$ associado a uma produtividade de $3.758 \mathrm{~kg} \mathrm{ha}^{-1}$ (Zobiole et al., 2010b). Apesar do teor foliar de $\mathrm{N}$ adequado, verifica-se que as produtividades dos híbridos foram maiores que nas variedades para o teor similar de N (Tabelas 3 e 4). Nesta situação a maior quantidade de folhas por planta nos híbridos pode ter contribuído para aumentar a produtividade uma vez que a disponibilidade de $\mathrm{N}$ por planta durante a fase de remobilização de nutrientes é maior. Zobiole et al. (2010a) verificaram que o $\mathrm{N}$ foi o nutriente mais exportado pelo aquênios.

Os híbridos apresentaram maior concentração de $\mathrm{P}$ na folha quando comparados com as variedades de polinização aberta (Tabelas 4). Entende-se que o solo não limitou a absorção de $\mathrm{P}$ devido à sua alta disponibilidade (Tabela 1) razão pela qual o maior número de folhas por planta pode estar relacionado com a capacidade dos híbridos em absorver mais $\mathrm{P}$, pois o sistema radicular mais robusto pode ser capaz de interceptar maior quantidade do nutriente e facilitar sua difusão no solo. Prado \& Leal (2006) observaram que a omissão de P, conjuntamente com o $\mathrm{N}$, foi a condição que mais reduziu o crescimento das folhas, do caule e da raiz. Esta interação entre os nutrientes pode estar relacionada com a participação do ATP na assimilação de N (Araújo \& Machado, 2006). Desta forma, maior quantidade de folhas por planta nos híbridos pode ter contribuído para aumentar a aquisição de carbono; consequentemente, maior

Tabela 3. Caracteres fenotípicos das cultivares de girassol no florescimento pleno e na colheita

\begin{tabular}{|c|c|c|c|c|c|c|}
\hline \multirow[b]{2}{*}{ Cultivar } & \multicolumn{3}{|c|}{ Caracteres no florescimento pleno } & \multicolumn{3}{|c|}{ Caracteres na colheita } \\
\hline & $\begin{array}{l}\text { Florescimento } \\
\text { (dias) }\end{array}$ & Altura $(\mathrm{cm})$ & $\mathrm{N}^{0}$ de folhas & $\begin{array}{l}\text { Ciclo } \\
\text { (dias) }\end{array}$ & $\begin{array}{l}\text { Massa de mil } \\
\text { aquênios (g) }\end{array}$ & $\begin{array}{l}\text { Produtividade } \\
\left(\mathrm{kg} \mathrm{ha}^{-1}\right)\end{array}$ \\
\hline Embrapa 122 V-2000 & $51 \mathrm{~d}$ & $179 \mathrm{a}$ & $19 d$ & $93 d$ & $82 \mathrm{a}$ & $3418 \mathrm{~b}$ \\
\hline Hélio 250 & $56 \mathrm{~b}$ & $176 \mathrm{a}$ & $24 \mathrm{~b}$ & $99 b$ & $86 a$ & $3950 \mathrm{a}$ \\
\hline Hélio 251 & $56 \mathrm{~b}$ & $187 \mathrm{a}$ & $23 \mathrm{~b}$ & $98 b$ & $66 \mathrm{~b}$ & $4631 \mathrm{a}$ \\
\hline Hélio 253 & $60 \mathrm{a}$ & $180 \mathrm{a}$ & $22 \mathrm{c}$ & $102 \mathrm{a}$ & $68 \mathrm{~b}$ & $4424 \mathrm{a}$ \\
\hline Dow Agroscience M 734 & $64 \mathrm{a}$ & $200 \mathrm{a}$ & $26 \mathrm{a}$ & $106 \mathrm{a}$ & $79 \mathrm{a}$ & $4457 \mathrm{a}$ \\
\hline Dow Agroscience MG 02 & $62 \mathrm{a}$ & $192 \mathrm{a}$ & $28 \mathrm{a}$ & $104 \mathrm{a}$ & $64 \mathrm{~b}$ & $4053 \mathrm{a}$ \\
\hline Média & 57 & 179 & 23 & 99 & 73 & 4053 \\
\hline $\mathrm{F}$ & $17,1^{\star \star}$ & $3,1^{\star}$ & $8,3^{\star \star}$ & $18,3^{\star \star}$ & $3,1^{*}$ & $7,5^{\star \star}$ \\
\hline C.V. (\%) & 3,3 & 8,8 & 8,9 & 1,8 & 12,4 & 10,2 \\
\hline
\end{tabular}

Médias seguidas pela mesma letra na coluna não diferem entre si pelo teste Scott Knott a 0,05 de probabilidade 


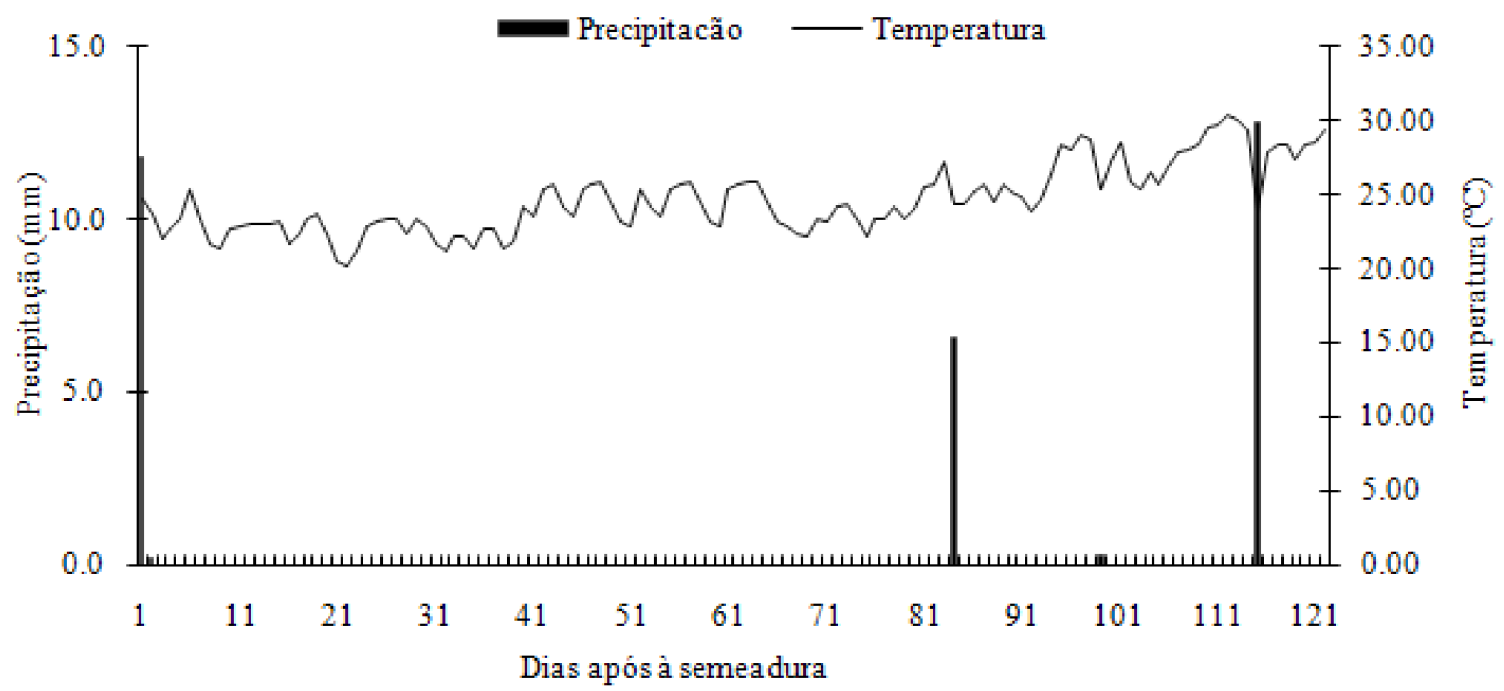

Figura 1. Precipitação e temperatura média durante o período de condução do experimento (junho a setembro de 2009)

Tabela 4. Teor de macronutrientes na folha índice de cultivares de girassol no florescimento pleno

\begin{tabular}{|c|c|c|c|c|c|c|}
\hline \multirow{2}{*}{ Cultivar } & $\mathbf{N}$ & $\mathbf{P}$ & K & $\mathrm{Ca}$ & $\mathrm{Mg}$ & S \\
\hline & \multicolumn{6}{|c|}{$\mathrm{g} \mathrm{kg}^{-1}$} \\
\hline IAC larama & 43,32 & $3,12 \mathrm{~b}$ & 42,26 & 31,78 & $6,11 b$ & $7,98 \mathrm{a}$ \\
\hline Hélio 250 & 43,16 & $3,59 \mathrm{a}$ & 36,95 & 35,69 & $6,35 a$ & $8,10 \mathrm{a}$ \\
\hline Hélio 251 & 40,04 & $3,80 \mathrm{a}$ & 32,63 & 35,43 & $6,35 \mathrm{a}$ & $7,44 b$ \\
\hline Hélio 253 & 39,99 & $3,60 \mathrm{a}$ & 41,41 & 33,31 & $6,00 \mathrm{~b}$ & $7,47 \mathrm{~b}$ \\
\hline Hélio 358 & 40,87 & $3,79 \mathrm{a}$ & 38,45 & 35,89 & $6,45 \mathrm{a}$ & $8,10 \mathrm{a}$ \\
\hline Hélio 360 & 40,61 & $3,96 \mathrm{a}$ & 33,58 & 32,73 & $6,08 \mathrm{~b}$ & $7,20 \mathrm{~b}$ \\
\hline Dow Agroscience M 734 & 38,12 & $3,44 \mathrm{a}$ & 32,02 & 32,15 & $5,96 b$ & $8,25 \mathrm{a}$ \\
\hline Dow Agroscience MG 02 & 44,71 & $3,56 \mathrm{a}$ & 34,06 & 34,68 & $6,45 \mathrm{a}$ & $7,82 \mathrm{a}$ \\
\hline Média & 40,91 & 3,51 & 35,91 & 33,91 & 6,23 & 7,88 \\
\hline $\mathrm{F}$ & $1,7^{\text {ns }}$ & $2,9^{*}$ & $1,4^{\mathrm{ns}}$ & $1,3^{\text {ns }}$ & $2,7^{*}$ & $3,1^{*}$ \\
\hline C.V. (\%) & 8,8 & 12,0 & 18,73 & 7,9 & 4,2 & 6,2 \\
\hline
\end{tabular}

Médias seguidas pela mesma letra na coluna não diferem entre si pelo teste Scott Knott a 0,05 de probabilidade

disponibilidade de carboidratos translocados para o enchimento dos aquênios dos híbridos. O teor médio de P está dentro da faixa de concentração considerada adequada, exceto no cultivar Embrapa 122 V-2000 (Castro \& Oliveira, 2005).

Não houve efeito das cultivares sobre o teor de $\mathrm{K}$ na folha índice (Tabela 4). O teor médio deste nutriente está de acordo com as faixas de concentração consideradas adequadas por Castro \& Oliveira (2005) e por Prado \& Leal (2006). Diferentemente, Zobiole et al. (2010a) constataram, em estudo da marcha de absorção, uma concentração de $54,8 \mathrm{~g} \mathrm{~kg}^{-1}$ de K considerada acima da faixa adequada.

Uchoa et al. (2011) relataram que aplicações excessiva de

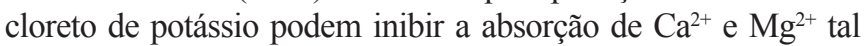
como a diminuição de $\mathrm{P}$, fato que não ocorreu neste experimento visto que os teores foliares de $\mathrm{Ca}$ e de $\mathrm{Mg}$ (Tabela 4) estão dentro da faixa considerada adequada, por Castro \& Oliveira (2005). A concentração média de $\mathrm{Ca}$ e $\mathrm{Mg}$ nas cultivares foi maior (Tabela 4) em relação à obtida por Prado \& Leal (2006). Esses autores explicaram que a omissão do Ca ocasiona diminuição do número de folhas, altura da planta, diâmetro do capítulo e da área foliar quando comparada com a do tratamento completo, haja vista que a omissão de $\mathrm{Mg}$ afeta tanto a área foliar como a matéria seca de raiz.

O teor de S nas folhas dos híbridos Hélio 251, 253 e 360 foi menor em relação aos dos demais cultivares (Tabela 4). Apesar desta diferença, os teores estão dentro da faixa considerada adequada, por Castro \& Oliveira (2005). Prado \& Leal (2006) observaram que o teor de $\mathrm{S}$ nas folhas estava adequado, mesmo quando o S foi omitido; este comportamento foi causado por uma provável concentração residual de $\mathrm{S}$ na água do tratamento sem S.

Os teores de $\mathrm{Zn}$, Mn e B apresentaram diferença significativa entre as cultivares (Tabela 5). Desses, o B foi o único micronutriente que apresentou tendência similar à da produtividade de aquênios. Pesquisas têm demonstrando que a faixa de concentração crítica de B na folha para o girassol está situada no intervalo de 46 a $60 \mathrm{mg} \mathrm{kg}^{-1}$ de B (Castro \& Oliveira, 2005; Rashid \& Rafique, 2005). Zobiole et al. (2011) observaram valor médio de 60,32 $\mathrm{mg} \mathrm{kg}^{-1}$ de B nas folhas para o cultivar BRS 191. Castro et al. (2006) comentaram que a absorção de B é facilitada quando o suprimento hídrico é adequado.

Os valores elevados para o teor de B na folha obtidos tanto para variedade como os híbridos, podem ser relacionados ao manejo adequado da irrigação e à alta disponibilidade de $\mathrm{B}$ no solo. Esta condição não foi prejudicial pois a produtividade média no experimento foi maior que as obtidas por Farias Neto et al. (2000). Prado \& Leal (2006) constataram o teor médio de $140 \mathrm{mg} \mathrm{kg}^{-1}$ observado no tratamento completo mais B e de 45 $\mathrm{mg} \mathrm{kg}^{-1}$ no tratamento sem B. Esses autores observaram que 
Tabela 5. Estado nutricional de cultivares de girassol no florescimento pleno

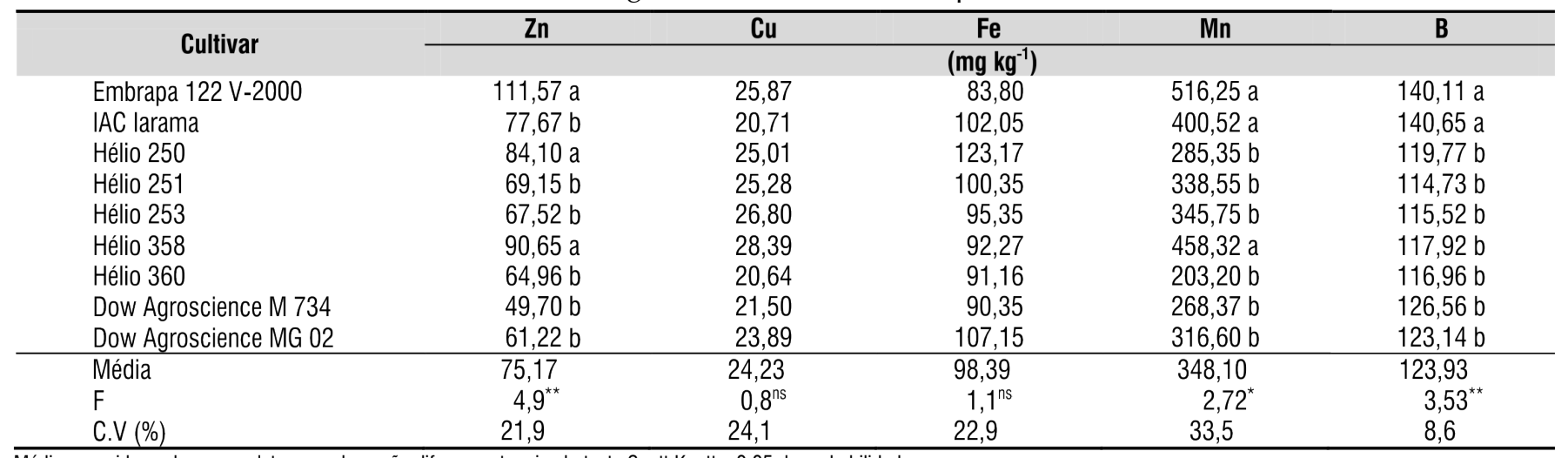

Médias seguidas pela mesma letra na coluna não diferem entre si pelo teste Scott Knott a 0,05 de probabilidade

o tratamento com B apresentou um número maior de folhas e massa seca da raiz em relação à omissão de $\mathrm{B}$.

O teor médio de $\mathrm{Zn}$ (Tabela 5) está acima da faixa considerada adequada por Castro \& Oliveira (2005). Diferentemente, Zobiole et al. (2011) e Prado \& Leal (2006) observaram uma concentração menor de Zn nas folhas. Mirzapour \& Khoshgoftar (2006) verificaram que a concentração de Zn de $162 \mathrm{mg} \mathrm{kg}^{-1}$ nas folhas prejudicou a produtividade de aquênios. Esta toxicidade não foi observada neste experimento, provavelmente pela utilização de cultivares com maior exigência neste nutriente.

$\mathrm{O} \mathrm{Mn}$ foi o micronutriente absorvido em maiores quantidades (Tabela 5). Esta concentração é praticamente o dobro da obtida por Zobiole et al. (2011). Dechen \& Nachtigall (2005) comentaram que elevadas concentrações de Mn no solo podem facilitar sua absorção. No presente estudo alta disponibilidade de Mn no solo pode ter favorecido sua aquisição pela planta (Tabela 1).

Para os nutrientes $\mathrm{Cu}$ e Fe verifica-se que não houve efeito das cultivares (Tabela 5). Teores de Cu na folha estão de acordo com os obtidos por Zobiole et al. (2011). Para o teor de Fe nas folhas observa-se que está abaixo do valor considerado adequado por Castro \& Oliveira (2005). Este comportamento pode ser atribuído à baixa disponibilidade de Fe no solo (Tabela 1). Entretanto, esta baixa concentração de Fe na folha não afetou a produtividade.

O maior teor de $\mathrm{P}$ nas folhas dos híbridos e o menor teor de $\mathrm{B}$ em relação às variedades não significam que tenha ocorrido interação entre os nutrientes, isto porque os mecanismos específicos de absorção e transporte que regulam o movimento do B e P entre as cultivares são diferentes (Araújo \& Machado, 2006; Dechen \& Nachtigall, 2005).

Em termos gerais, o estado nutricional equilibrado e o manejo adequado da irrigação associados às condições de temperatura favorável ao crescimento de girassol, foram os responsáveis pelas altas produtividades tanto dos híbridos como das variedades de polinização aberta. Silva et al. (2011) obtiverem produtividade média de $4.085 \mathrm{~kg} \mathrm{ha}^{-1}$ com aplicação diária de lâmina de irrigação, correspondente a $150 \%$ da evapotranspiração do tanque classe $\mathrm{A}$.

Apesar do girassol ser tipicamente cultivado em safrinha (Castro \& Oliveira, 2005; Silva et al., 2007) e apontado como tolerante à deficiência hídrica (Castro \& Farias, 2005; Toureiro et al., 2007), esta espécie responde positivamente à irrigação (Silva et al., 2009; Silva et al., 2011). O adequado suprimento hídrico associado ao solo corrigido e as condições climáticas favoráveis, permitiram a obtenção de elevadas produtividades no presente estudo.

\section{Conclusões}

1. O número de folhas por planta no florescimento pleno é maior nos híbridos Hélio 250, Hélio 251, Hélio 253, Hélio 358, Hélio 360, Dow Agroscience M 734 e MG 02 em relação as cultivares de polinização aberta Embrapa 122 V-2000 e IAC Iarama.

2. Os teores foliares de $\mathrm{N}, \mathrm{K}, \mathrm{Ca}, \mathrm{Cu}$ e $\mathrm{Fe}$ não são influenciados pelas cultivares de girassol; os de $\mathrm{Mg}, \mathrm{S}, \mathrm{Mn}$ e $\mathrm{Zn}$ se apresentaram distintos entre as cultivares.

3. O teor de P na folha índice dos híbridos é maior que nos cultivares Embrapa 122 V-2000 e IAC Iarama.

4. O teor de B na folha índice dos híbridos é maior que nas variedades de polinização aberta.

5. Os híbridos Hélio 250, Hélio 251, Hélio 253, Hélio 358, Hélio 360, Dow Agroscience M 734 e MG 02 apresentam maior produtividade que as cultivares de polinização aberta Embrapa 122 V-2000 e IAC Iarama.

\section{AgRADECIMENTOS}

Ao Conselho Nacional de Desenvolvimento Científico e Tecnológico $(\mathrm{CNPq})$, pela bolsa de doutorado concedida ao segundo autor; ao CNPq e à Fundação de Amparo à Pesquisa de Minas Gerais (FAPEMIG), pelo apoio financeiro à pesquisa; as Empresas Dow Agrocience, Heliagro e Embrapa, pela doação das sementes dos cultivares.

\section{Literatura Citada}

Aguiar Neto, P.; Oliveira, F. A.; Marques, L. F.; Rodrigues, A. F.; Santos, F. G. B. Efeitos da aplicação do fósforo no crescimento da cultura do girassol. Revista Verde de Agrecologia e Desenvolvimento Sustentável, v.5, p.148$155,2010$.

Allen, R. G.; Pereira, L. S.; Raes, D.; Smith, M. Evapotraspiración del cultivo. Utah State University. Guías para la determinación de los requerimientos de agua de los cultivos. Rome: FAO, 2006. 323p. Paper, 56. 
Amabile, R. F.; Guimarães, D. P.; Farias Neto, A. L. Análise de crescimento de girassol em Latossolo com diferentes níveis de saturação por base no cerrado. Pesquisa Agropecuária Brasileira, v.38, p.219-224, 2003.

Andrade, F. H.; Calvino, P.; Cirilo, A.; Barbieri, P. Yield responses to narrow rows depend on increased radiation interception. Agronomy Journal, v.94, p.975-980, 2002.

Araújo, A. P.; Machado, C. T. T. Fósforo. In: Nutrição mineral de plantas. Fernandes, M.S. (ed.) 1.ed. Viçosa: Sociedade Brasileira de Ciência do Solo, 2006. Cap 10, p.253-280.

Bernardo, S.; Soares, A. A.; Mantovani, E. C. Manual de irrigação. Viçosa: UFV, 2006. 625p.

Biscaro, G. A.; Machado, J. R.; Tosta, M. S.; Mendonça, V.;Soratto, R. P.; Carvalho, L.A. Adubação nitrogenada em cobertura no girassol irrigado nas condições de Cassilândia-MS. Ciência eAgrotecnologia, v.32, p.13661373, 2008.

Braz, M. R. S.; Rossetto, C. A. V. Acúmulo de nutrientes e rendimento de óleo em plantas de girassol influenciadas pelo vigor dos aquênios e pela densidade de semeadura. Semina: Ciências Agrárias, v.31, p.1193-1204, 2010.

Castro, C.; Farias, J. R. B. Ecofisiologia do girassol. In: Leite, R. M. V. B. C.; Brighrnti, A. M.; Castro, C. Girassol no Brasil. 1.ed. Londrina: Embrapa Soja, 2005. p.317-365.

Castro, C.; Moreira, A.; Oliveira, R. F.; Dechen, A. R. Boro e estresse hídrico na produção do girassol. Ciência e Agrotecnologia, v.30, p.214-220, 2006.

Castro, C.; Oliveira, F. A. Nutrição e adubação do girassol. In: Leite, R. M. V. B. C.; Brighrnti, A. M.; Castro, C. Girassol no Brasil. 1.ed. Londrina: Embrapa Soja, 2005. p.317-365.

CONAB - Companhia Brasileira de Abastecimento. Série histórica de produtividade de 1977 a 2011. http://www. conab.br. 07 Jun. 2011.

Dechen, A. R.; Nachtigall, G. R. Micronutrientes. In: Nutrição mineral de plantas. Fernandes, M. S. (ed.) 1.ed. Viçosa: Sociedade Brasileira de Ciência do Solo, 2006. p.253-280.

Farias Neto, A. L.; Amabile, R. F.; Azevedo, J. A.; Fonseca, C. E. L.; Castiglioni, V. B. Avaliação de variedades de girassol nos cerrados do Distrito Federal. Revista Ceres, v.47, p.469-482, 2000.

Ivanoff, M. E. A.; Uchôa, S. C. P.; Alves, J. M. A.; Smiderle, O. J.; Sediyama, T. Formas de aplicação de nitrogênio em três cultivares de girassol na savana de Roraima. Revista Ciência Agronômica, v.41, p.319-325, 2010.

Malavolta, E.; Vitti, G. C.; Oliveira, S. A. Avaliação do estado nutricional das plantas: Princípios e aplicações. 2.ed. Piracicaba: Potafos, 1997. 319p.

Mirzapour, M. H.; Khoshgoftar, A. H. Zinc application effects on yield and seed oil content of sunflower grown on a saline calcareous soil. Journal of Plant Nutrition, v.29, p.1719$1727,2006$.
Palmer, S. J.; Berridge, D. M.; Mcdonald, A. J. S.; Davies, W. J. Control of leaf expansion in sunflower (Helianthus annuusL.) by nitrogen nutrition. Journal of Experimental Botany, v.47, p.359-368, 1996.

Porto, W. S.; Carvalho, C. G. P.; Pinto, R. J. B.; Oliveira, M. F.; Oliveira, A. C. B. Adaptabilidade e estabilidade de genótipos de girassol para a região subtropical do Brasil. Ciência Rural, v.39, p.2452-2459, 2009.

Prado, R. M.; Leal, R. M. Desordens nutricionais por deficiência em girassol variedade Catissol-01. Pesquisa Agropecuária Tropical, v.36, p.187-193, 2006.

Rashid, A.; Rafique, E. Internal boron requirement of young sunflower plants: Proposed diagnostic criteria. Communications in Soil Science and Plant Analysis, v.36, p.2113-2119, 2005.

SAEG - Sistema para análises estatísticas, versão 9.1. Viçosa: UFV, 2007.

Santos, L. G.; Souza, U. O.; Primo, D. C.; Silva, P. C. C.; Santos, A. R. Estado nutricional da cultura do girassol submetida à adubação com fósforo e boro. Enciclopédia Biosfera, v.6, p.1-14, 2010.

Silva, A. G.; Moraes, E. B.; Pires, R.; Carvalho, C. G. P.; Oliveira, A. C. B. Efeitos do espaçamento entre linhas nos caracteres agronômicos de três híbridos de girassol cultivados na safrinha. Pesquisa Agropecuária Tropical, v.39, p.105-110, 2009.

Silva, A. R. A.; Bezerra, F. M. L.; Sousa, C. C. M.; Pereira Filho, J. V.; Freitas, C. A. S. Desempenho de cultivares de girassol sob diferentes lâminas de irrigação no Vale do Curu, CE. Revista Ciência Agronômica, v.42, p.57-64, 2011.

Smiderle, O. J.; Mourão Júnior, M.; Gianluppi, D. Avaliação de cultivares de girassol em savana de Roraima. Acta Amazônica, v.35, p.331-336, 2005.

Toureiro, C. M.; Serralheiro, R. P.; Oliveira, M. R. Resposta das culturas do girassol e do milho a diferentes cenários de rega deficitária. Revista de Ciências Agrárias, v.30, p.33-47, 2007.

Uchôa, S. C. P.; Ivanoff, M. E. A.; Alves, J. M. A.; Smiderle, O. J.; Sediyama, T. Adubação de potássio em cobertura nos componentes de produção de cultivares de girassol. Revista Ciência Agronômica, v.42, p.8-15, 2011.

Zobiole, L. H. S.; Castro, C.; Oliveira, F.A.; Oliveira Júnior, A. Marcha de absorção de macronutrientes na cultura do girassol. Revista Brasileira Ciência do Solo, v.34, p.425433, 2010a.

Zobiole, L. H. S.; Castro, C; Oliveira, F. A.; Oliveira Júnior, A.; Moreira, A. Curva de crescimento, estado nutricional, teor de óleo e produtividade do girassol hibrido BRS 191 cultivado no estado do Paraná. Revista Brasileira de Óleos e Fibrosos, v.14, p.55-62, 2010 b.

Zobiole, L. H. S.; Castro, C.; Oliveira, F. A.; Oliveira Júnior, A.; Moreira, A. Sunflower micronutrient uptake curves. Ciência e Agrotecnologia, v.35, p.346-353, 2011. 